\title{
A molecular test based on RT-LAMP for rapid, sensitive and inexpensive colorimetric detection of SARS-CoV-2 in clinical samples
}

\section{Catarina Amaral}

Instituto de Tecnologia Química e Biológica António Xavier, Universidade Nova de Lisboa

\section{Wilson Antunes}

Centro de Investigação da Academia Militar, Unidade Militar Laboratorial de Defesa Biológica e Química

\section{Elin Moe}

Instituto de Tecnologia Química e Biológica António Xavier, Universidade Nova de Lisboa

Américo G. Duarte

Instituto de Tecnologia Química e Biológica António Xavier, Universidade Nova de Lisboa

Luís M. P. Lima

Instituto de Tecnologia Química e Biológica António Xavier, Universidade Nova de Lisboa

\section{Cristiana Santos}

Instituto de Tecnologia Química e Biológica António Xavier, Universidade Nova de Lisboa

\section{Inês L. Gomes}

Centro de Investigação da Academia Militar, Unidade Militar Laboratorial de Defesa Biológica e Química

Gonçalo S. Afonso

Instituto de Tecnologia Química e Biológica António Xavier, Universidade Nova de Lisboa

\section{Ricardo Vieira}

Centro de Investigação da Academia Militar, Unidade Militar Laboratorial de Defesa Biológica e Química

\section{Helena Sofia S. Teles}

Centro de Medicina Naval - Marinha Portuguesa

\section{Marisa Reis}

Centro de Medicina Naval - Marinha Portuguesa

\section{Manuel A. Ramalho Silva}

Hospital das Forças Armadas

\section{Ana Margarida Henriques}

Instituto Nacional de Investigação Agrária e Veterinária, I.P.,Laboratório de Virologia

\section{Miguel Fevereiro}

Instituto Nacional de Investigação Agrária e Veterinária, I.P.,Laboratório de Virologia

\section{Rita Ventura}

Instituto de Tecnologia Química e Biológica António Xavier, Universidade Nova de Lisboa

\section{Mónica Serrano}


Instituto de Tecnologia Química e Biológica António Xavier, Universidade Nova de Lisboa

Catarina Pimentel ( $\square$ pimentel@itqb.unl.pt)

Instituto de Tecnologia Química e Biológica António Xavier, Universidade Nova de Lisboa

\section{Research Article}

Keywords: SARS-CoV-2, RT-LAMP, colorimetric detection

Posted Date: May 4th, 2021

DOl: https://doi.org/10.21203/rs.3.rs-180877/v1

License: (c) (i) This work is licensed under a Creative Commons Attribution 4.0 International License. Read Full License

Version of Record: A version of this preprint was published at Scientific Reports on August 12th, 2021. See the published version at https://doi.org/10.1038/s41598-021-95799-6. 
1 A molecular test based on RT-LAMP for rapid, sensitive and inexpensive colorimetric detection of SARS-CoV-2 in clinical samples

3

4

5

6

7

Catarina Amaral ${ }^{1}$, Wilson Antunes ${ }^{2}$, Elin Moe ${ }^{1}$, Américo G. Duarte $^{1}$, Luís M. P. Lima ${ }^{1}$, Cristiana Santos ${ }^{1}$, Inês L. Gomes ${ }^{2}$, Gonçalo S. Afonso ${ }^{1}$, Ricardo Vieira ${ }^{2}$, Helena Sofia S. Teles ${ }^{3}$, Marisa S. Reis ${ }^{3}$, Manuel A. Ramalho da Silva ${ }^{4}$, Ana Margarida Henriques ${ }^{5}$, Miguel Fevereiro ${ }^{5}$, M. Rita Ventura ${ }^{1}$, Mónica Serrano ${ }^{1^{\star}}$, Catarina Pimentel $1^{{ }^{*}}$

${ }^{1}$ Instituto de Tecnologia Química e Biológica António Xavier, Universidade Nova de Lisboa, Av. República, 2780-157 Oeiras, Portugal.

${ }^{2}$ Centro de Investigação da Academia Militar (CINAMIL), Unidade Militar Laboratorial de Defesa Biológica e Química (UMLDBQ), Av. Dr. Alfredo Bensaúde, 1849-012 Lisboa, Portugal.

${ }^{3}$ Centro de Medicina Naval - Marinha Portuguesa, Alfeite, 2810-001 Almada, Portugal.

${ }^{4}$ Hospital das Forças Armadas, Azinhaga dos Ulmeiros, 1649-020 Lisboa, Portugal.

${ }^{5}$ Instituto Nacional de Investigação Agrária e Veterinária, I.P.,Laboratório de Virologia, Av. República, Quinta do Marquês, 2780-157 Oeiras, Portugal.

* email: serrano@itqb.unl.pt; pimentel@itqb.unl.pt 


\section{Abstract}

2

3 Until there is an effective implementation of COVID-19 vaccination program, a robust 4 testing strategy, along with prevention measures, will continue to be the most viable 5 way to control disease spread. Such a strategy should rely on disparate diagnostic 6 tests to prevent a slowdown in testing due to lack of materials and reagents imposed 7 by supply chain problems, which happened at the beginning of the pandemic.

8 In this study, we have established a single-tube test based on RT-LAMP that enables 9 the visual detection of less than 100 viral genome copies of SARS-CoV-2 within 30 10 minutes. We benchmarked the assay against the gold standard test for COVID-19 11 diagnosis, qRT-PCR, using 177 nasopharyngeal RNA samples. For $\mathrm{Ct} \leq 32$, the RT12 LAMP assay had a sensitivity of $100 \%$ and a specificity of $96.1 \%$. Additionally, we set up a RNA extraction-free RT-LAMP test capable of detecting SARS-CoV-2 directly from saliva samples, albeit with lower sensitivity. The saliva was self-collected and the collection tube remained closed until inactivation, thereby ensuring the protection of the testing personnel. As expected, RNA extraction from saliva samples increased the sensitivity of the test. To lower the costs associated with RNA extraction, we performed this step using an alternative protocol that uses plasmid DNA extraction columns. We also produced the enzymes needed for the assay and established an in-house-made RT-LAMP test independent of specific distribution channels. Finally, we developed a new colorimetric method that allowed the detection of LAMP products by the visualization of an evident color shift, regardless of the reaction $\mathrm{pH}$. 


\section{Introduction}

A robust population-scale testing strategy for SARS-CoV-2 based on rapid, reliable, decentralized and affordable diagnostic tests is of utmost priority to guide public health interventions. This testing approach aligned with measures such as mask wearing, frequent hand washing and social distancing may be enough to prevent and contain major outbreaks while COVID-19 vaccination programs are in progress.

The gold standard of COVID-19 testing is quantitative RT-PCR (qRT-PCR), which detects the genetic material of SARS-CoV-2 in nasopharyngeal (NP) samples. Although very reliable, qRT-PCR diagnostics are complex, laborious and expensive, and its worldwide use caused, in the early stages of the pandemic, a shortage of reagents needed for sample collection and viral RNA extraction. Thus, qRT-PCRbased tests, in their current format, are unlikely to serve the purposes of a mass testing of the population.

Loop-mediated isothermal amplification (LAMP) is a DNA amplification method that allows rapid and sensitive detection of a specific gene ${ }^{1-3}$. LAMP merged with reverse transcription (RT-LAMP) has been successfully used for the detection of several respiratory RNA viruses ${ }^{4-8}$, including SARS-CoV-2 (reviewed in ${ }^{9}$ ). RT-LAMP is a powerful alternative to qRT-PCR due to its high specificity and sensitivity, costeffectiveness, and fast turnaround time (typically 30 minutes). In RT-LAMP, the amplification of the genetic material of the virus occurs at a constant temperature and, therefore, diagnostic tests based on RT-LAMP can be carried out anywhere with basic resources, as they only require a heat block or a water bath set to a single temperature. The reaction products can be analyzed by means of conventional DNAintercalating dyes, agarose gel electrophoresis, UV-light illumination, or real-time fluorescence ${ }^{10}$. Alternatively, end-point colorimetric readouts are also possible through the detection of reaction by-products, such as pyrophosphate and protons, which are released during DNA polymerization, after the incorporation of deoxynucleotide triphosphates. LAMP colorimetric methods detect the turbidity, triggered by the accumulation of magnesium pyrophosphate ${ }^{1}$, or color changes, occurring when complexometric indicators ${ }^{3,11}, \mathrm{pH}$ sensitive dyes ${ }^{12}$ or even DNAintercalating dyes ${ }^{13-15}$ are incorporated into the reaction. The simple technical and instrumental requirements of colorimetric RT-LAMP tests make them extremely attractive for point-of-care (POC) use and implementation in low-resource settings. 
1 Colorimetric RT-LAMP has been successfully used for detection of SARS-CoV-2 in

2 NP fluids from COVID-19 patients ${ }^{15-24}$.

3 Recently, it was shown that SARS-CoV-2 could be detected in the saliva of infected

4 individuals, highlighting salivary tests as valuable alternatives for COVID-19

5 diagnosis ${ }^{25-27}$. Saliva-based testing has numerous advantages over NP sampling,

6 especially in a mass screening scenario. It can be performed easily and non-

7 invasively, thus minimizing patient discomfort, and it does not require specialized

8 personnel or the use of protective equipment, which saves time and reduces costs.

9 For these reasons, saliva qRT-PCR and RT-LAMP tests for SARS-CoV-2 detection

10 have been widely explored in recent months ${ }^{28-31}$.

In the current study, we have established and evaluated a RT-LAMP colorimetric test for SARS-CoV-2 detection from RNA samples extracted from the NP fluid, or directly from the saliva, of COVID-19 patients. We have also developed a new colorimetric detection method based on a complexometric indicator that, when merged to LAMP, is capable of detecting SARS-CoV2 with great analytical sensitivity. In addition, we have produced the enzymes needed for the test and implemented an in-house-made assay fully independent of commercial reagents.

With this work, we join efforts with many other authors who, in the last months, have been testing and validating alternative tests for the detection of SARS-CoV-2 in order to make the molecular diagnosis of COVID-19 more accessible and to facilitate its large-scale implementation, even in settings that lack economic or infrastructural resources. 


\section{Results}

\section{Sensitivity of two different RT-LAMP colorimetric setups}

The main components of the RT-LAMP colorimetric reaction are two enzymes (a reverse transcriptase $(\mathrm{RT})$ and a strand displacement polymerase), a colorimetric dye (phenol red) and a primer set (typically composed of six primers) ${ }^{12}$. To detect SARS-CoV-2 using RT-LAMP, we took advantage of the primer set previously validated in vitro by Zhang et al. ${ }^{24}$ and tested, on clinical specimens from large cohorts of COVID-19 patients, by several other authors ${ }^{16-19}$. The primer set $(\mathrm{N}-\mathrm{A})$ targeted the $\mathrm{N}$ gene, which encodes the nucleocapsid protein and has the most abundant expression of subgenomic mRNA during infection ${ }^{32-35}$.

We tested two different assay formats. In one format, we used the WarmStart Colorimetric LAMP 2x Master Mix (New England Biolabs), which includes all the reagent components with the exception of the primers. In the other, we purchased the separate enzymes (RTx and Bst 2.0) from New England Biolabs, while the reaction buffer with the colorimetric dye (phenol red) were prepared in-house as described by Tanner et al. ${ }^{12}$. The analytical sensitivities of these two setups were evaluated and compared by assaying in parallel tenfold serial dilutions of an in vitro transcribed N-gene RNA standard (IVT RNA), starting from $10^{5}$ copies down to 10 copies (per $20 \mu \mathrm{L}$ reaction), at tenfold intervals (Fig. 1A). Color changes from pink (negative) to yellow (positive) were registered after a 30-minute incubation period at $65^{\circ} \mathrm{C}$, as we found that for extended periods (up to 60 minutes), negative controls often turned yellowish. The amplification of the IVT RNA was confirmed by agarose gel electrophoresis (Fig. 1B). Ten replicates were analyzed per assay format (Fig. 1C) and IVT RNA dilutions were simultaneously analyzed by qRT-PCR (Fig. 1D). The limit of detection (LoD) was reliably found to be between 100-1000 viral copies for the assay using the WarmStart Colorimetric LAMP 2x Master Mix (Fig. 1A), whereas for that using the separate components the LoD was consistently one Log10 lower (10-100 copies). However, for half of the replicates, a tenfold lower LoD was achieved for both test formats (Fig. 1C). Such stochastic detection efficiency has been reported by others (1), and therefore we defined 100-1000 (WarmStart Colorimetric LAMP 2x Master Mix) and 10-100 (reaction with separate components) as the robust limits of detection.

For the same serial dilution range, the qRT-PCR assay was able to consistently detect down to 10 copies per reaction (mean $\mathrm{Ct}=35.22$ ) (Fig. 1D). Compared to qRT- 
1 PCR, the RT-LAMP assay, depending on the test setup, detected up to ten- or one

2 hundred-fold less copies of viral RNA. As the RT-LAMP format using the separate

3 components was consistently more sensitive, we decided to choose this setup in

4 subsequent assays.

5

6 Sensitivity and specificity of the colorimetric RT-LAMP assay in detecting viral RNA from the nasopharyngeal fluid

We investigated whether the RT-LAMP assay, using separate components, could be used to accurately detect SARS-CoV-2 in clinical samples. For that purpose, we tested a set of surplus RNA samples extracted from the nasopharyngeal (NP) fluid of 177 individuals who were previously tested for COVID-19, using the standard clinical qRT-PCR testing. The samples comprised 126 RNA samples that tested positive (qRT-PCR positive, $\mathrm{Ct} \leq 40$ ) and 51 samples that tested negative (qRT-PCR negative, $\mathrm{Ct} \geq 40$ ). As shown in Fig. $2 \mathrm{~A}$, after incubation for 30 minutes at $65^{\circ} \mathrm{C}$, a pink to yellow color change was visualized in all RT-LAMP reactions estimated to have more than 100 RNA molecules present in the reaction (qRT-PCR positive, $\mathrm{Ct} \leq 32$, Fig. 1C), which is in agreement with the observed experimental sensitivity (Fig. 1A). We found two false positives, i.e. two qRT-PCR negative samples that scored positive in the RT-LAMP assay (Table 1). Thus, the overall specificity of the assay was $96.1 \%(\mathrm{Cl}$ : $87-99 \%)$ and the sensitivity for samples with $\mathrm{Ct} \leq 32$ was $100 \%$ (Cl: $94.7-100 \%)$. For lower viral load, as measured by qRT-PCR ( $\mathrm{Ct}>32$ ), the assay showed a decrease in diagnostic sensitivity (Table 1, Fig. 2B).

Overall, these results indicate a robust performance of the colorimetric RT-LAMP assay across a broad range of purified RNA samples.

Sensitivity of the colorimetric RT-LAMP assay in detecting SARS-CoV-2 in saliva samples

We next optimized our RT-LAMP assay for direct detection of SARS-CoV-2 in saliva samples. To reduce the risk associated with handling samples containing infectious viral particles, saliva was self-collected into a tube and placed at $95^{\circ} \mathrm{C}$ for 30 minutes, for inactivation. This simple heat inactivation procedure has been shown to enable an effective genetic detection of SARS-CoV-2 by other authors ${ }^{30,31}$. After a brief centrifugation step that significantly improved assay reliability (data not shown), the supernatant was diluted with $\mathrm{TE}$, to buffer basal $\mathrm{pH}$ differences in saliva, and 
1 immediately analyzed or stored at $-80^{\circ} \mathrm{C}$. Lalli et al. have shown that TE is LAMP-

2 compatible and does not affect the assay sensitivity ${ }^{29}$.

3 We determined the LoD of the assay using both the IVT RNA standard and viral

4 SARS-CoV-2 particles spiked into healthy human saliva to simulate clinical samples.

5 We were able to detect 100 IVT RNA copies (Fig. 3A) and 24 SARS-CoV-2 viral

6 particles (Fig. 3B) per reaction in only 30 minutes after inactivation, using our RT-

7 LAMP protocol. Since at this sensitivity the assay would detect the typical viral load of

8 SARS-CoV-2 found in the saliva of COVID-19 patients (100-1000 genomes per $\mu \mathrm{l}){ }^{36}$, 9 we proceeded to test the clinical samples.

Saliva and matched NP swab specimens of 49 individuals infected with SARS-CoV-2 (as previously determined by qRT-PCR) were collected and analyzed by RT-LAMP (saliva) and qRT-PCR (NP fluid). In addition, 15 saliva samples of healthy donors were tested by RT-LAMP. Saliva samples were self-collected as described above, and individuals were asked not to eat or drink before testing. A set of 10 of the 49 COVID-19-positive patients was asked to induce salivation by placing the tongue on the salivary sublingual glands. For this group, we could only detect SARS-CoV-2 sequences in the saliva of one patient using the direct RT-LAMP assay (Fig. 4A). However, after RNA extraction, 8 out of 10 individuals were identified as being SARSCoV-2-positive. We assumed that by stimulating salivation we were diluting the saliva viral load, which might have accounted for a high number of false negatives. Corroborating this idea, for all other positive samples where salivation was not induced, we obtained a good correlation with the qRT-PCR results (Fig. 4B and C), as 33 out of 39 samples were identified as positive samples, with no false positives registered. Therefore, the direct RT-LAMP assay had a sensitivity of $85 \%(\mathrm{Cl}: 70-$ 93\%) for saliva samples with matched NP swabs with Ct $\leq 28$ (Fig. 4C). Reaction volumes, but not saliva amounts, were scaled up to increase the assay sensitivity (Fig.4B).

All saliva samples that were falsely negative by direct RT-LAMP were positive after RNA extraction (Fig. 4B). This step increases by 4-9 times the estimated cost of the assay $(1 €)$. Inspired by the work of Yaffe et al. ${ }^{37}$, to keep RT-LAMP affordable, we tested whether we could use silica columns routinely used in molecular biology laboratories to purify bacterial plasmids (mipreps), to extract viral RNA from saliva samples. As shown in Fig. 4D, false negative samples were found to be positive after RNA purification using this method, with an estimated cost per RT-LAMP test of $2 €$. 
1 Development of an in-house-made colorimetric RT-LAMP

2 Aiming to establish a colorimetric RT-LAMP test fully independent of commercial 3 suppliers, we produced the two enzymes needed for the assay and benchmarked 4 them against commercial alternatives using IVT RNA of SARS-CoV-2.

5 As for the strand displacement polymerase, the gene encoding the large (Klenow)

6 fragment of Geobacillus stearothermophilus was synthesized, with codon optimized

7 for expression in E. coli, and inserted into the pET28+ vector. After a simple 2-step

8 purification protocol, we ended up with $250 \mu \mathrm{L}$ of $B s t \mathrm{LF}$, at a concentration of 7.6

$9 \mathrm{mg} / \mathrm{mL}$. We next determined the LoD of the assay combining $1 \mu \mathrm{L}$ of the purified Bst

$10 \mathrm{LF}, 50$-fold diluted $(0.15 \mu \mathrm{g}$ per $20 \mu \mathrm{L}$ reaction), the in-house-made colorimetric 11 reaction buffer, and RTx (New England Biolabs). This semi-commercial assay 12 consistently detected 1-10 copies of the SARS-CoV-2 $\mathrm{N}$ gene per reaction (Fig. 5A). We found that, under our colorimetric conditions, Bst LF outperformed Bst 2.0 (New England Biolabs) (Fig 5A and $1 \mathrm{~A}$ ). The amount of the produced Bst LF was enough to perform 12500 tests at that analytical sensitivity (1-10 copies). Alternatives to the commercial RTx were also explored. We started by testing several non-thermostable reverse transcriptases (from NZYtech and Roche), but it was not possible to detect LAMP products with an acceptable sensitivity (less than $10^{6}$ viral IVT RNA copies per reaction, data not shown). We also expressed and purified the MashUP RT enzyme (clone available at https://pipettejockey.com) that, when combined with Bst 2.0, was able to detect down to 10 IVT viral RNA copies (Fig. 5B), a LoD similar to the one obtained with the commercial enzyme (Fig. 5A). The MashUP purification consists of a single-step protocol, and sufficient enzyme was obtained to perform 500 assays $(0.5 \mu \mathrm{L}$ corresponding to $3.4 \mu \mathrm{g} / \mu \mathrm{L}$ were used directly in the reaction). Finally, we combined the produced enzymes (Bst LF and MashUP) with the homemade colorimetric reaction mixture and assessed (i) the LoD of the assay (Fig. $5 \mathrm{C}$ ) and (ii) whether this setup could identify SARS-CoV-2 N-gene sequences in the RNA extracted from the NP fluid of COVID-19 patients (Fig. 5D). Our in-house-made assay successfully detected SARS-CoV-2 viral sequences in all the three COVID-19 patients' samples (Fig. 5D). Moreover, when using patients' saliva, processed as described above, instead of NP RNA, the assay was also capable of identifying SARS-CoV-2 infected patients (Fig. 5E). Corroborating the work of Alekseenko et al. ${ }^{38}$, these results clearly indicate that, using simple expression and purification protocols and home-made buffers, it is possible to establish a colorimetric assay, fully 
1 independent of specific supply chains, that efficiently detects SARS-CoV-2 RNA

2 sequences from clinical specimens.

4 A new colorimetric method for detection of RT-LAMP amplification products

5 The strong and evident color shift observed with phenol red renders this $\mathrm{pH}$-sensitive

6 dye much preferred for end-point colorimetric detection of LAMP products. However,

7 when the phenol red method is used with crude samples, interference of the sample

$8 \mathrm{pH}$ with the assay readout is often observed. Indeed, when establishing the direct

9 RT-LAMP saliva protocol, we had to discard one sample due to the initial acidification of the reaction, as a strong color shift to yellow was observed immediately after sample addition into the reaction mixture. Although several colorimetric indicators are available for detection of LAMP products ${ }^{3,11-15}$, the pale color shift they produce, which is difficult to distinguish by the naked eye, has certainly restrained their wide use. To overcome these limitations, we developed a new colorimetric detection method based on the complexometric indicator, murexide (MX), which forms a complex with divalent zinc $\left(\mathrm{Zn}^{2+}\right)^{39}$. In the absence of $\mathrm{Zn}^{2+}, \mathrm{MX}$ has a pink color, whereas in the presence of the divalent cation it turns yellow. Because pyrophosphate (PPi) forms a strong complex with zinc, we reasoned that the PPi released during DNA polymerization would displace $\mathrm{Zn}^{2+}$ cations from $\mathrm{MX}$, inducing a color change from yellow to pink. By mimicking the reaction components in a test tube containing the $\mathrm{Zn}-\mathrm{MX}$ complex, an evident color shift from yellow to pink was observed immediately after PPi addition (Fig. 6A). Unfortunately, we found that Zn, but not MX, strongly inhibited the LAMP reaction (data not shown), making it impossible to use $\mathrm{Zn-MX}$ in a one-step colorimetric assay. Therefore, after an incubation period at $65^{\circ} \mathrm{C}$ for 30 minutes, the tubes were opened and $\mathrm{MX}(0.5 \mathrm{mM})$ and $\mathrm{ZnCl}_{2}(2.5 \mathrm{mM})$ were added to the reaction. To avoid carryover problems due to the post-amplification opening of the tubes, this step was performed in a separate room.

Using the in-house produced enzymes, we first compared the sensitivity of $Z n-M X$ with that of phenol red using IVT RNA (Fig. 6B and C). Like phenol red, Zn-MX showed an evident color difference depending on the presence (pink) or absence (yellow) of LAMP amplification. Moreover, the method enabled the clear detection of SARS-CoV-2 in crude saliva samples of nine COVID-19 positive patients (Fig. 6D), whereas with phenol red the viral genetic material was only identified in eight of these samples (Fig. 6E). 


\section{Discussion}

2 Widespread testing, preferably based on different supply chains, is required to curtail

3 the ongoing pandemic. To address that need, we have in this work evaluated a

4 LAMP-based colorimetric test to rapidly detect SARS-CoV-2 in RNAs extracted from

5 patient's NP fluids, using a single tube protocol. The assay also allows for detection

6 of the virus directly from patient's saliva with minimal processing and increased protection of the testing personnel. We also showed that using simple expression and purification protocols together with homemade buffers, it is possible to establish an inexpensive colorimetric assay, fully independent of specific supply chains, that efficiently detects SARS-CoV-2 RNA. While not as sensitive as the reference diagnostic method for COVID-19, qRT-PCR, the simplicity, turnaround time and low associated costs of our test make it an attractive and efficient tool for infection control. According to existing literature, the LoD of the test is sufficient to identify individuals with viral titers high enough to transmit the virus (300-1000 viral copies per $\mu \mathrm{L}){ }^{27,40,41}$. This test sensitivity is understood to be adequate for surveillance and screening of the asymptomatic population. The availability of such a testing solution is therefore of great importance, as infectiousness peaks occur before or at the symptoms onset ${ }^{42}$. Indeed, the rapid evolution of COVID-19 has been partly attributed to transmissions occurring through people who are presymptomatic or asymptomatic ${ }^{43}$; efforts to implement a strategy enabling communities to test asymptomatic individuals require urgent attention and testing tools to support it. Several authors have recently shown that the use of different primer sets boosts RTLAMP sensitivity, possibly due to better primer efficiency and/or higher target abundance. Also different saliva treatment protocols, combining certain chemicals and proteinase $\mathrm{K}$, have been shown to improve SARS-CoV-2 detection in saliva samples $16,21,22,28,29,31$. Thus, we reason that there is still room to improve the sensitivity of our test. As expected, RNA extraction greatly improved the saliva test sensitivity, by increasing the concentration of the viral sequences in the sample. Many other authors have reported similar findings ${ }^{21,22,44,45}$ and extensive efforts have been made to establish alternative protocols that enable RNA enrichment using fast and inexpensive methodologies ${ }^{21,22}$. Here we showed that RNA extraction using common plasmid DNA extraction columns is an economical way to concentrate and purify viral RNA from saliva samples. 
1 To eliminate the impact of acidic saliva samples on the test readout, we have

2 developed a new colorimetric reading, independent of changes in the $\mathrm{pH}$ of the

3 LAMP reaction. The method uses a divalent zinc salt (such as $\mathrm{ZnCl}_{2}$ ) and the

4 complexometric indicator murexide to form a transient complex (Zn-MX). The

5 presence of $\mathrm{PPi}$, a by-product of the reaction, is indicated by the indicator

6 displacement method, since $\mathrm{Zn}^{2+}$ forms a more stable complex with PPi and thus

7 releases murexide. As the presence of zinc inhibits the amplification reaction, the

8 metal can only be added at the end of the reaction, thus requiring the tubes to be

9 opened post-amplification. This procedure poses the threat of carryover 10 contaminations, very common in LAMP reactions ${ }^{46,47}$, which leads to false positives.

11 We therefore do not anticipate that the Zn-MX method, in its current formulation, can

12 be used routinely in a molecular diagnostic laboratory. However, the molecular 13 saliva-based tests currently available for COVID-19, whose workflow already 14 demands opening the LAMP reaction tube, may certainly benefit from our method ${ }^{48}$. 15 Additionally, the method can be safely used in closed systems using microfluidic 16 diagnostic cartridges, similar to the one recently described by Ganguli et al. ${ }^{49}$.

17 Overall, this study, while addressing some of the testing bottlenecks imposed by the current pandemic, reinforces RT-LAMP as a powerful method for sensitive and inexpensive molecular diagnosis of COVID-19 that can be easily deployable in limited resource settings. 


\section{Materials and Methods}

\section{Sample Collection, Processing and storage}

Clinical specimens were collected at Hospital das Forças Armadas and processed in Laboratório de Bromatologia e Defesa Biológica (Unidade Militar Laboratorial de Defesa Biológica e Química). Saliva specimens ( 1ml) were self-collected into sterile tubes (50 mL or $1.5 \mathrm{~mL}$ ). Patients were asked not to eat or drink before testing. NP swab-matched samples were collected in parallel and placed in $3 \mathrm{ml}$ Universal Viral Transport Media. Tubes containing clinical specimens were decontaminated with an alcohol-based solution and identified. After collection, samples were kept at $4^{\circ} \mathrm{C}$ for 2-4 days or processed immediately. Samples were inactivated by incubation at $95^{\circ} \mathrm{C}$ for 5 minutes (NP swabs) or 30 minutes (saliva samples). Salivas were centrifuged at $5000 \mathrm{~g}$ for 5 minutes and $200 \mu \mathrm{L}$ of the supernatant were diluted in TE $10 \mathrm{x}$ (1x, final concentration) and frozen at $-80^{\circ} \mathrm{C}$ until analysis. The saliva pellets were also frozen.

\section{RNA extraction from clinical samples}

Total viral RNA was extracted from $140 \mu \mathrm{l}$ of NP deactivated samples using Viral RNA Mini Kit (QIAGEN) and eluted in $60 \mu$ of RNAse free water, to ensure the RNA elution buffer has no impact of $\mathrm{pH}$ in RT-LAMP reactions. As for saliva samples, total RNA (from the pellets) was isolated using the RNeasy Mini Kit (QIAGEN) following the manufacturer's instructions or the LogSpin method ${ }^{37}$ as described by the authors. Briefly, the pellet was mixed by vortexing with $250 \mu \mathrm{L}$ a guanidine-based solution (8M guanidine- $\mathrm{HCl}, 20 \mathrm{mM}$ MES hydrate and $20 \mathrm{mM}$ EDTA). The mixture was centrifuged at $16000 \mathrm{~g}$ for $5 \mathrm{~min}$ and the supernatant was mixed with $250 \mu \mathrm{L}$ of $100 \%$ ethanol, and loaded into the ZR plasmid miniprep columns (ZYMO Research). The column was washed twice with $450 \mu \mathrm{l}$ of $3 \mathrm{M}$ Na-Acetate and $320 \mu \mathrm{l}$ of $70 \%$ ethanol. RNA was eluted in $30 \mu$ of water.

\section{SARS-CoV-2 RNA standard}

To prepare the SARS-CoV-2 RNA standard, the $\mathrm{N}$ gene was amplified from the plasmid 2019-nCoV_N_Positive Control (Integrated DNA Technologies) with a T7promoter-containing primer TAATACGACTCACTATAGGatgtctgataatggaccccaaaa - 3') and the reverse primer (5'- ttaggcctgagttgagtcagc-3'), then the product was in vitro transcribed using the HiScribe T7 High Yield RNA Synthesis Kit, NEB), according to the manufacturer's 
1 instructions. Template DNA was removed using Turbo DNase (Invitrogen) and RNA

2 was then purified using the RNeasy Mini Kit (QIAGEN). Standard RNA copy numbers

3 were calculated from concentration measured using Take3 from Epoch from Biotek

4 and confirmed using a Ultrospec2100pro (Amersham Biosciences).

5

\section{Virus isolation and spike experiments}

SARS-Cov-2 isolate, BetaCoV/Portugal/ICV1006/2020, was obtained at INIAV from a patient confirmed positive for SARS-CoV-2 by qRT-PCR. Virus isolation and production of the virus stock were accomplished in Vero E6 cells (African green monkey kidney cells, catalog no.ATCC CRL-1586) maintained in Eagle's minimum essential medium (MEM) supplemented with $10 \%$ fetal bovine serum (FBS), penicillin $(100 \mathrm{U} / \mathrm{ml})$ and streptomycin $(100 \mathrm{mg} / \mathrm{ml})$, at $37^{\circ} \mathrm{C}$ in a $5 \%$ carbon dioxide atmosphere. The infectivity titer of the viral stock prepared from infected cell culture supernatants was determined by a standard plaque assay. Aliquots of saliva (500 $\mu \mathrm{l})$ were spiked with decreasing numbers of plaque forming units (pfus) of isolate ICV1006 and used to evaluate the limit of detection of the saliva RT-LAMP assay.

\section{qRT-PCR}

SARS-CoV-2 N-gene and an internal control (RNase P) were amplified by qRT-PCR using the TaqMan 2019-nCoV Assay Kit v1 (Termofisher) with TaqMan Fast Virus 1step Master Mix (Termofisher) and the CFX96 thermocyler (BioRad), according to the manufacturer's instructions.

\section{RT-LAMP assays}

RT-LAMP reaction was performed in a total volume of $20 \mu \mathrm{L}$ containing the following components: $8 \mathrm{U}$ Bst 2.0 (NEB), $7.5 \mathrm{U}$ RTx (NEB) and 1x colorimetric buffer mix (1.6 $\mu \mathrm{M}$ FIP/BIP primers, $0.4 \mu \mathrm{M}$ LF/LB primers, $0.2 \mu \mathrm{M}$ F3/B3 primers Gene N-A ${ }^{24}, 10$ $\mathrm{mM}\left(\mathrm{NH}_{4}\right)_{2} \mathrm{SO}_{4}$ (Merck), $50 \mathrm{mM} \mathrm{KCl}(\mathrm{BDH}), 8 \mathrm{mM} \mathrm{MgSO}{ }_{4}(\mathrm{BDH}), 0.1 \%$ Tween 20, 0.2 mM Phenol Red (Sigma), $1.4 \mathrm{mM}$ each dNTP (NZYTech)). For the in-house-made assay, we used the same colorimetric buffer mix, $0.5 \mu \mathrm{L}$ of MashUP RT $(6.8 \mathrm{mg} / \mathrm{ml})$ and $1 \mu \mathrm{L}$ of Bst LF (7.6 mg/ml) 50x diluted. WarmStart colorimetric LAMP 2x master mix (M1800S, NEB) was also used with the above final primer concentration. When the complexometric indicator MX-Zn was used, samples were assembled as described above, but without phenol red. After $30 \mathrm{~min}, 2 \mu \mathrm{L}$ of $5 \mathrm{mM}$ Murexide and 1 $\mu \mathrm{L}$ of $50 \mathrm{mM}$ of $\mathrm{ZnCl}_{2}$ were added to the reaction, in a post-LAMP workspace. All 
reactions were performed in a thermocycler at $65^{\circ} \mathrm{C}$ and pictures were taken at the indicated time points. Figures depicting the readout of the RT-LAMP assays are representative of three independent experiments.

\section{Zinc-Murexide colorimetric method}

All reagents obtained from commercial sources in analytical grade. Analytical solutions were prepared in ultrapure grade water from a Milli-Q system, as follows: MOPS buffer $\mathrm{pH}=7.4$ at $20 \mathrm{mM}$, magnesium chloride $\left(\mathrm{MgCl}_{2}\right)$ at $47.5 \mathrm{mM}$, zinc chloride $\left(\mathrm{ZnCl}_{2}\right)$ at $47.1 \mathrm{mM}$, sodium pyrophosphate $\left(\mathrm{Na}_{4} \mathrm{P}_{2} \mathrm{O}_{7}\right)$ at $50 \mathrm{mM}$, ATP at 25 $\mathrm{mM}$, and murexide $(\mathrm{MX})$ at $0.5 \mathrm{mM}$. The $\mathrm{MX}$ solution was prepared immediately before use or otherwise kept frozen. Samples $(1 \mathrm{~mL})$, simulating the starting conditions of the RT-LAMP assay, contained $8 \mathrm{mM}$ of magnesium chloride and 1.4 $\mathrm{mM}$ of ATP, buffered at $\mathrm{pH}=7.4$ with $10 \mathrm{mM}$ of MOPS. To these samples were added a few drops of a MX solution to attain a suitable color intensity, which turned the samples violet, indicating that $\mathrm{MX}$ was in the free form. Addition of $\mathrm{ZnCl}_{2}$ at $8 \mathrm{mM}$ to the samples rendered them orange, indicating a change of the indicator to its complexed form. Finally, titration of pyrophosphate into the samples caused a color change back to pink from ca. $16 \mathrm{mM}$, pointing to a release of the indicator caused by the binding of zinc to pyrophosphate. These color changes demonstrated that $\mathrm{MX}$ is a suitable colorimetric indicator to detect pyrophosphate in presence of magnesium.

\section{Expression and purification of Bst1 Klenow}

The gene encoding the klenow fragment of Bst1 (UniProt sequence P52026, residue 291 - 876) was synthesized (codon optimized for expression in E.coli) and inserted into the pET28+ vector with nucleotides encoding an N-terminal 6HisTag and a TEV cleavage site (Genescript). The resulting plasmid was used for transformation of $E$. coli BL21 (DE3) pLysS. Overnight pre-cultures $(10 \mathrm{ml})$ were grown at $37^{\circ} \mathrm{C}$ and used to inoculate $1 \mathrm{~L}$ Power Broth (Molecular Dimensions) with $100 \mu \mathrm{g} \mathrm{mL}^{-1}$ ampicillin and $50 \mu \mathrm{g} \mathrm{mL}^{-1}$ kanamycin. The culture was grown at $37^{\circ} \mathrm{C}$ until $\mathrm{OD}_{600}$ reached $0.7-0.9$. At this point, the culture was moved to $18^{\circ} \mathrm{C}$ and expression was induced by adding 0.5 $\mathrm{mM}$ isopropyl- $\beta$-d-thiogalactopyranoside (IPTG). After overnight expression, the cells were harvested by centrifugation at $7548 \mathrm{~g}$ for 30 minutes at $4^{\circ} \mathrm{C}$, flash frozen and stored at $-20^{\circ} \mathrm{C}$. Upon protein purification, the cells were resuspended in $20 \mathrm{~mL}$ extraction buffer $(150 \mathrm{mM} \mathrm{NaCl}, 50 \mathrm{mM}$ Tris- $\mathrm{HCl} \mathrm{pH} 7.5,10 \mathrm{mM} \mathrm{MgCl} 2,1 \mathrm{mg} / \mathrm{mL}$ DNase I, $1 \mathrm{mg} / \mathrm{mL}$ lysozyme and one tablet EDTA free proteinase inhibitor (Roche)) 
1 and subjected to multiple freeze/thaw cycles (alternating room temperature water

2 bath and liquid nitrogen). The lysate was cleared by centrifugation at $48385 \mathrm{~g}$ for 30

$3 \mathrm{~min}$ at $4^{\circ} \mathrm{C}$ and the supernatant was carefully removed and added to a $5 \mathrm{~mL}$ HisTrap

4 HP purification column (Cytiva), previously equilibrated in buffer $\mathrm{A}$ (150 mM NaCl, 50

$5 \mathrm{mM}$ Tris- $\mathrm{HCl} \mathrm{pH}$ 7.5). The protein was eluted over a $10 \mathrm{CV}$ gradient from $5-100 \%$

6 buffer $\mathrm{B}$ (buffer $\mathrm{A}$ with $0.5 \mathrm{M}$ Imidazol). Fractions containing Bst1 Klenow were identified by SDSPAGE, pooled and dialyzed overnight in $2 \mathrm{~L}$ buffer $A$ in the presence of TEV $(1: 20)$ at $4^{\circ} \mathrm{C}$. The dialyzed and TEV cleaved protein was thereafter added to a $5 \mathrm{~mL}$ HisTrap column and eluted in the Flow Through (due to the removal of the HisTag). The HisTag free Bst1 Klenow was thereafter desalted through a HiTrap desalting column (Cytiva) followed by a final purification step on a $5 \mathrm{ml} \mathrm{HiTrap}$ Heparin HP column (Cytiva), to remove eventual residual DNA bound to the protein. The protein was eluted over a $10 \mathrm{CV}$ gradient in buffer $\mathrm{B} 2$ (buffer $\mathrm{A}$ and $1 \mathrm{M} \mathrm{NaCl}$ ). Fractions containing BstKlenow was identified by SDSPAGE, pooled, concentrated to $7.6 \mathrm{mg} / \mathrm{ml}$ by Amicon Ultra-15 concentration filter units (10 kDa cut off, Millipore) and stored at $-80^{\circ} \mathrm{C}$.

\section{Expression and purification of MashUP reverse transcriptase}

The MashUp RT plasmid (kindly provided by https://pipettejockey.com), which encodes a modified Feline Leukemia Virus Reverse Transcriptase (RT) and plasmid pGTf2 that encodes for a chaperon were co-transformed into E. coli BL21 (DE3) competent cells and plated on L-Broth (LB) agar (NZYTech) plates containing 50 $\mu \mathrm{g} / \mathrm{mL}$ kanamycin and $30 \mu \mathrm{g} / \mathrm{mL}$ chlorophenicol. Overnight cultures were inoculated with fresh transformants and grown at $37{ }^{\circ} \mathrm{C}, 150$ RPM in LB selective medium. Subsequently, the overnight culture was diluted 100x in Terrific Broth (TB). The cells were grown at $37{ }^{\circ} \mathrm{C}, 150-170 \mathrm{RPM}$ until OD $600 \mathrm{~nm}$ reach 0.8-1.0. Then, temperature was lowered to $18^{\circ} \mathrm{C}$ and protein expression induced with $0.5 \mathrm{mM}$ IPTG and $5 \mathrm{ng} / \mathrm{mL}$ tetracycline, for the RT and chaperone, respectively, and grown additionally for $18 \mathrm{~h}$ at $18{ }^{\circ} \mathrm{C}$. The cells were harvested by centrifugation at $4500 \times g$ for $10 \mathrm{~min}$ at $4{ }^{\circ} \mathrm{C}$ and resuspended in MashUp-RT lysis buffer $(25 \mathrm{mM}$ Tris- $\mathrm{HCl} \mathrm{pH}$ 8, $300 \mathrm{mM} \mathrm{NaCl}, 10 \%$ glycerol, $40 \mathrm{mM}$ imidazole, 0.5\% Triton X-100), supplemented with one tablet of Complete EDTA-free protease inhibitor cocktail (one unit per1 L). Cells were disrupted by French press and the extract was clarified by centrifugation at $100000 \mathrm{xg}, 90$ minutes at $4^{\circ} \mathrm{C}$. The supernatant was loaded into an IMAC column equilibrated with lysis buffer. The column was washed with the same buffer and the 
adsorbed proteins were eluted from the column with $25 \mathrm{mM}$ Tris- $\mathrm{HCl} \mathrm{pH} 8,300 \mathrm{mM}$

$\mathrm{NaCl}, 10 \%$ glycerol, $500 \mathrm{mM}$ imidazole, $0.5 \%$ Triton $\mathrm{X}-100$. Protein was concentrated in an Ammicon ultrafiltration device with a $30 \mathrm{kDa}$ cutoff. Total protein present in the sample was quantified by BCA assay $(6.8 \mathrm{mg} / \mathrm{mL})$ using albumin as a standard.

\section{Ethics statement}

The Director of the Hospital das Forças Armadas (HFA) approved all experimental procedures, which were carried out following the guidelines of the HFA Ethics Committee. The study was conducted in accordance with the European Statements for Good Clinical Practice and the declaration of Helsinki of the World Health Medical Association. Informed consent was obtained from all participants.

\section{Acknowledgments}

We thank the members of the COVID-19 task force of ITQB NOVA and Mariana Pinho for helpful discussions and suggestions. In particular, we thank Claudio M. Soares and Adriano O. Henriques for their unconditional support and invaluable help in making this work possible. The authors acknowledge the assistance of Paula Chicau, ITQB NOVA, in the development of the saliva test and are grateful to Chuck Farah, São Paulo University, for the pGTf2 plasmid. This work was supported by (i) Project LISBOA-01-0145-FEDER-007660 ("Microbiologia Molecular, Estrutural e Celular") funded by FEDER funds through COMPETE2020 - "Programa Operacional Competitividade e Internacionalização" (POCI), (ii) the European Union's Horizon 2020 research and innovation programme under grant agreement No 810856 and (iii) "Fundação para a Ciência e a Tecnologia" (FCT) through programme IF (IF/00124/2015) to C.P and through the project "DETECT: Development of an Easy, fast-Track and Economical Colorimetric Test for autonomous national diagnosis of COVID-19" Ref 433_613549914 (20/7/153), attributed to C.P., under the scope of the $2^{\text {nd }}$ edition of the programme RESEARCH4COVID19.

\section{Author contributions}

Conceptualization: CA and CP. Performed the experiments: CA, WA, CS, ILG, GSA, RV, MS, CP. Enzyme expression and purification: EM and AGD. Colorimetric method development: CA, MRV, LMPL, CP. Virus isolation: AMH and MF. Sample collection: HSST, MSR, MARS. Writing - original draft: CP, Writing - review \& editing: CA, MS, WA, EM, AGD, LMPL, ILG, MF, RV, CP. Project administration: MS and CP. Funding acquisition: $\mathrm{CP}$.

\section{Competing interests}

The authors declare no competing interests. 


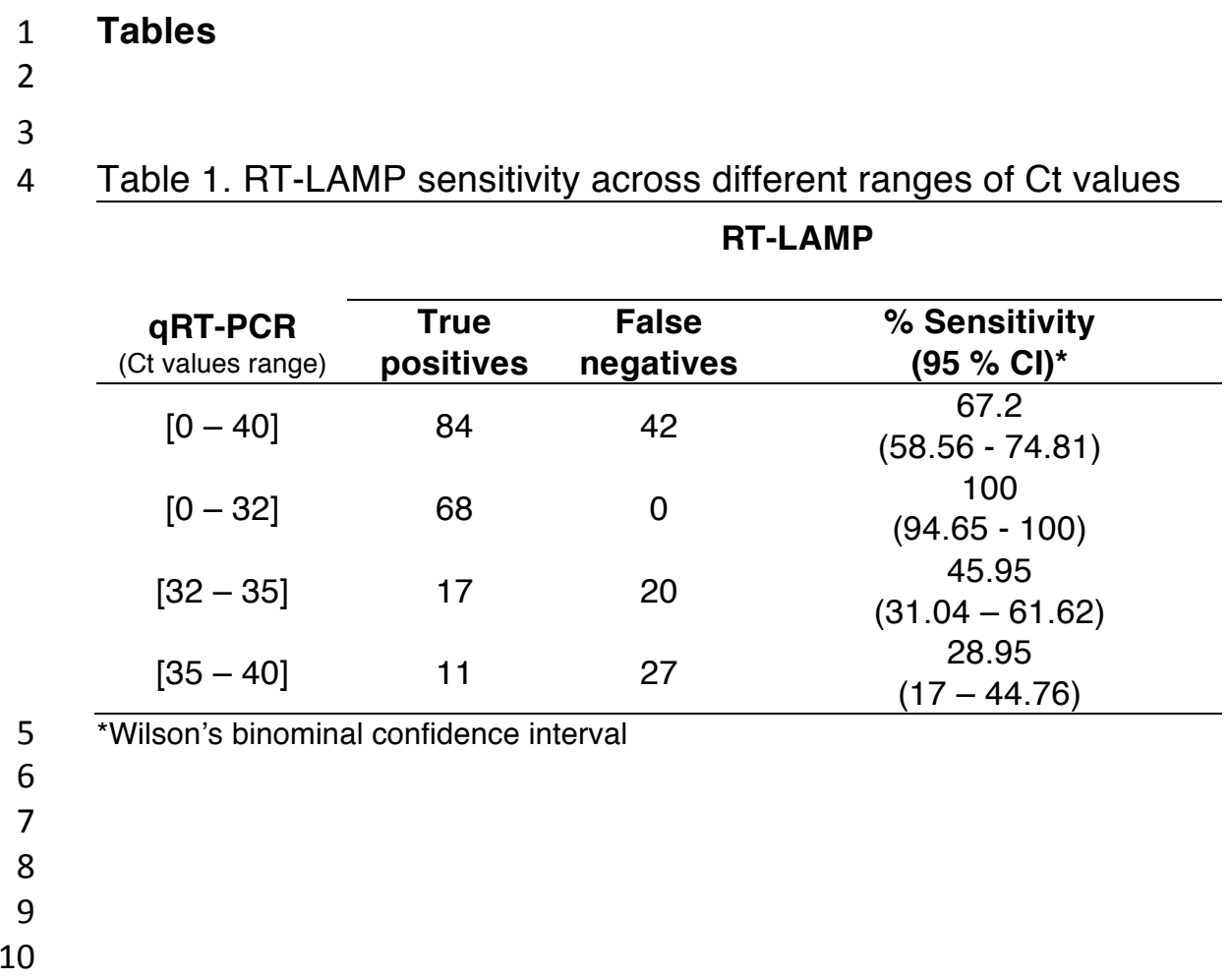




\section{References}

1 Nagamine, K., Hase, T. \& Notomi, T. Accelerated reaction by loop-mediated isothermal amplification using loop primers. Mol Cell Probes 16, 223-229, doi:10.1006/mcpr.2002.0415 (2002).

2 Notomi, T. et al. Loop-mediated isothermal amplification of DNA. Nucleic Acids Res 28, E63, doi:10.1093/nar/28.12.e63 (2000).

3 Tomita, N., Mori, Y., Kanda, H. \& Notomi, T. Loop-mediated isothermal amplification (LAMP) of gene sequences and simple visual detection of products. Nat Protoc 3, 877-882, doi:10.1038/nprot.2008.57 (2008).

4 Ahn, S. J. et al. Rapid and simple colorimetric detection of multiple influenza viruses infecting humans using a reverse transcriptional loop-mediated isothermal amplification (RT-LAMP) diagnostic platform. BMC Infect Dis 19, 676, doi:10.1186/s12879-019-4277-8 (2019).

5 Bhadra, S. et al. Real-time sequence-validated loop-mediated isothermal amplification assays for detection of Middle East respiratory syndrome coronavirus (MERS-CoV). PLoS One 10, e0123126, doi:10.1371/journal.pone.0123126 (2015).

6 Hong, T. C. et al. Development and evaluation of a novel loop-mediated isothermal amplification method for rapid detection of severe acute respiratory syndrome coronavirus. J Clin Microbiol 42, 1956-1961, doi:10.1128/jcm.42.5.1956-1961.2004 (2004).

7 Jayawardena, S. et al. Loop-mediated isothermal amplification for influenza $A$ (H5N1) virus. Emerg Infect Dis 13, 899-901, doi:10.3201/eid1306.061572 (2007).

8 Lee, S. H. et al. One-Pot Reverse Transcriptional Loop-Mediated Isothermal Amplification (RT-LAMP) for Detecting MERS-CoV. Front Microbiol 7, 2166, doi:10.3389/fmicb.2016.02166 (2016).

9 Thompson, D. L., Y. Recent progress in RT-LAMP enabled COVID-19 detection. Sensors and Actuators Reports 2, doi:10.1016/j.snr.2020.100017 (2020).

10 Quyen, T. L., Ngo, T. A., Bang, D. D., Madsen, M. \& Wolff, A. Classification of Multiple DNA Dyes Based on Inhibition Effects on Real-Time Loop-Mediated Isothermal Amplification (LAMP): Prospect for Point of Care Setting. Front Microbiol 10, 2234, doi:10.3389/fmicb.2019.02234 (2019).

11 Goto, M., Honda, E., Ogura, A., Nomoto, A. \& Hanaki, K. Colorimetric detection of loop-mediated isothermal amplification reaction by using hydroxy naphthol blue. Biotechniques 46, 167-172, doi:10.2144/000113072 (2009).

12 Tanner, N. A., Zhang, Y. \& Evans, T. C., Jr. Visual detection of isothermal nucleic acid amplification using pH-sensitive dyes. Biotechniques 58, 59-68, doi:10.2144/000114253 (2015).

13 Fischbach, J., Xander, N. C., Frohme, M. \& Glokler, J. F. Shining a light on LAMP assays--a comparison of LAMP visualization methods including the novel use of berberine. Biotechniques 58, 189-194, doi:10.2144/000114275 (2015).

14 Lamb, L. E., Bartolone, S. N., Ward, E. \& Chancellor, M. B. Rapid detection of novel coronavirus/Severe Acute Respiratory Syndrome Coronavirus 2 (SARSCoV-2) by reverse transcription-loop-mediated isothermal amplification. PLoS One 15, e0234682, doi:10.1371/journal.pone.0234682 (2020).

15 Park, G. S. et al. Development of Reverse Transcription Loop-Mediated Isothermal Amplification Assays Targeting Severe Acute Respiratory Syndrome Coronavirus 2 (SARS-CoV-2). J Mol Diagn 22, 729-735, doi:10.1016/j.jmoldx.2020.03.006 (2020). 
16 Anahtar, M. N. et al. Clinical assessment and validation of a rapid and sensitive SARS-CoV-2 test using reverse-transcription loop-mediated isothermal amplification. medRxiv, 2020.2005.2012.20095638, doi:10.1101/2020.05.12.20095638 (2020).

17 Buck, M. D. et al. Standard operating procedures for SARS-CoV-2 detection by a clinical diagnostic RT-LAMP assay. medRxiv, 2020.2006.2029.20142430, doi:10.1101/2020.06.29.20142430 (2020).

18 Butler, D. J. et al. Shotgun Transcriptome and Isothermal Profiling of SARS-CoV2 Infection Reveals Unique Host Responses, Viral Diversification, and Drug Interactions. bioRxiv, 2020.2004.2020.048066, doi:10.1101/2020.04.20.048066 (2020).

19 Dao Thi, V. L. et al. A colorimetric RT-LAMP assay and LAMP-sequencing for detecting SARS-CoV-2 RNA in clinical samples. Sci Transl Med 12, doi:10.1126/scitransImed.abc7075 (2020).

20 Huang, W. E. et al. RT-LAMP for rapid diagnosis of coronavirus SARS-CoV-2. Microb Biotechnol 13, 950-961, doi:10.1111/1751-7915.13586 (2020).

21 Kellner, M. J. et al. A rapid, highly sensitive and open-access SARS-CoV-2 detection assay for laboratory and home testing. bioRxiv, 2020.2006.2023.166397, doi:10.1101/2020.06.23.166397 (2020).

22 Rabe, B. A. \& Cepko, C. SARS-CoV-2 detection using isothermal amplification and a rapid, inexpensive protocol for sample inactivation and purification. Proc Natl Acad Sci U S A 117, 24450-24458, doi:10.1073/pnas.2011221117 (2020).

$23 \mathrm{Yu}$, L. et al. Rapid Detection of COVID-19 Coronavirus Using a Reverse Transcriptional Loop-Mediated Isothermal Amplification (RT-LAMP) Diagnostic Platform. Clin Chem 66, 975-977, doi:10.1093/clinchem/hvaa102 (2020).

24 Zhang, Y. et al. Rapid Molecular Detection of SARS-CoV-2 (COVID-19) Virus RNA Using Colorimetric LAMP. medRxiv, 2020.2002.2026.20028373, doi:10.1101/2020.02.26.20028373 (2020).

25 To, K. K. et al. Temporal profiles of viral load in posterior oropharyngeal saliva samples and serum antibody responses during infection by SARS-CoV-2: an observational cohort study. Lancet Infect Dis 20, 565-574, doi:10.1016/S14733099(20)30196-1 (2020).

26 To, K. K. et al. Consistent Detection of 2019 Novel Coronavirus in Saliva. Clin Infect Dis 71, 841-843, doi:10.1093/cid/ciaa149 (2020).

27 Wyllie, A. L. et al. Saliva or Nasopharyngeal Swab Specimens for Detection of SARS-CoV-2. N Engl J Med 383, 1283-1286, doi:10.1056/NEJMc2016359 (2020).

28 Dudley, D. M. et al. Optimizing direct RT-LAMP to detect transmissible SARSCoV-2 from primary nasopharyngeal swab and saliva patient samples. medRxiv, 2020.2008.2030.20184796, doi:10.1101/2020.08.30.20184796 (2020).

29 Lalli, M. A. et al. Rapid and extraction-free detection of SARS-CoV-2 from saliva with colorimetric LAMP. medRxiv, 2020.2005.2007.20093542, doi:10.1101/2020.05.07.20093542 (2020).

30 Ranoa, D. R. E. et al. Saliva-Based Molecular Testing for SARS-CoV-2 that Bypasses RNA Extraction. bioRxiv, 2020.2006.2018.159434, doi:10.1101/2020.06.18.159434 (2020).

31 Yang, Q. et al. Saliva TwoStep: An RT-LAMP saliva test for SARS-CoV-2 and its assessment in a large population. medRxiv, 2020.2007.2016.20150250, doi:10.1101/2020.07.16.20150250 (2020).

$32 \mathrm{Kim}, \mathrm{D}$. et al. The Architecture of SARS-CoV-2 Transcriptome. Cell 181, 914-921 e910, doi:10.1016/j.cell.2020.04.011 (2020). 
33 Lai, M. M. \& Cavanagh, D. The molecular biology of coronaviruses. Adv Virus Res 48, 1-100 (1997).

$34 \mathrm{Li}, \mathrm{S}$. et al. The epitope study on the SARS-CoV nucleocapsid protein. Genomics Proteomics Bioinformatics 1, 198-206, doi:10.1016/s1672-0229(03)01025-8 (2003).

$35 \mathrm{Wu}, \mathrm{H}$. Y. \& Brian, D. A. Subgenomic messenger RNA amplification in coronaviruses. Proc Natl Acad Sci U S A 107, 12257-12262, doi:10.1073/pnas.1000378107 (2010).

36 Zhu, J., Guo, J., Xu, Y. \& Chen, X. Viral dynamics of SARS-CoV-2 in saliva from infected patients. The Journal of infection 81, e48-e50, doi:10.1016/j.jinf.2020.06.059 (2020).

37 Yaffe, H. et al. LogSpin: a simple, economical and fast method for RNA isolation from infected or healthy plants and other eukaryotic tissues. BMC Research Notes 5, 45, doi:10.1186/1756-0500-5-45 (2012).

38 Alekseenko, A. et al. Detection of SARS-CoV-2 using non-commercial RT-LAMP regents and raw samples. medRxiv, 2020.2008.2022.20179507, doi:10.1101/2020.08.22.20179507 (2020).

39 Schwarzenbach, G. F., W. Complexometric Titrations. 2nd edn, 60-62, 260 (1969).

40 Lescure, F.-X. et al. Clinical and virological data of the first cases of COVID-19 in Europe: a case series. The Lancet Infectious Diseases 20, 697-706, doi:10.1016/S1473-3099(20)30200-0 (2020).

41 Wolfel, R. et al. Virological assessment of hospitalized patients with COVID2019. Nature 581, 465-469, doi:10.1038/s41586-020-2196-x (2020).

$42 \mathrm{He}, \mathrm{X}$. et al. Temporal dynamics in viral shedding and transmissibility of COVID19. Nature Medicine 26, 672-675, doi:10.1038/s41591-020-0869-5 (2020).

43 Moghadas, S. M. et al. The implications of silent transmission for the control of COVID-19 outbreaks. Proceedings of the National Academy of Sciences 117, 17513-17515, doi:10.1073/pnas.2008373117 (2020).

44 Broughton, J. P. et al. CRISPR-Cas12-based detection of SARS-CoV-2. Nature Biotechnology 38, 870-874, doi:10.1038/s41587-020-0513-4 (2020).

45 Klein, S. et al. SARS-CoV-2 RNA Extraction Using Magnetic Beads for Rapid Large-Scale Testing by RT-qPCR and RT-LAMP. Viruses 12, 863, doi:10.3390/v12080863 (2020).

46 Hsieh, K., Mage, P. L., Csordas, A. T., Eisenstein, M. \& Tom Soh, H. Simultaneous elimination of carryover contamination and detection of DNA with uracil-DNA-glycosylase-supplemented loop-mediated isothermal amplification (UDG-LAMP). Chemical Communications 50, 3747-3749, doi:10.1039/C4CC00540F (2014).

$47 \mathrm{Ma}, \mathrm{C}$. et al. A novel method to control carryover contamination in isothermal nucleic acid amplification. Chemical Communications 53, 10696-10699, doi:10.1039/C7CC06469A (2017).

48 Helgouach, N. et al. EasyCOV : LAMP based rapid detection of SARS-CoV-2 in saliva. medRxiv, 2020.2005.2030.20117291, doi:10.1101/2020.05.30.20117291 (2020).

49 Ganguli, A. et al. Rapid isothermal amplification and portable detection system for SARS-CoV-2. Proceedings of the National Academy of Sciences 117, 22727, doi:10.1073/pnas.2014739117 (2020). 


\section{Figure 1}

A

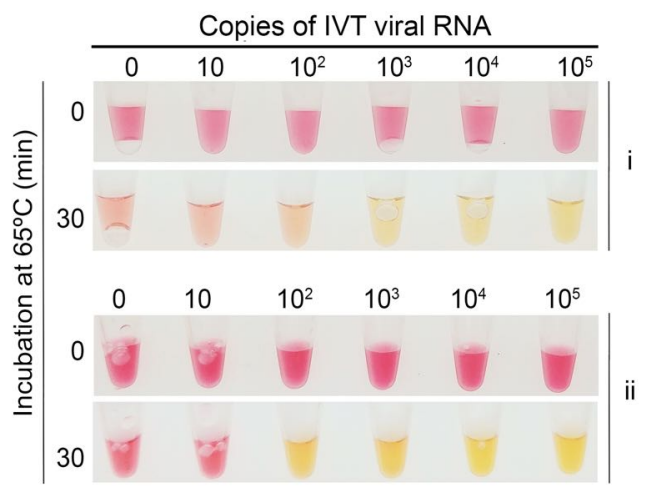

C

\begin{tabular}{ccc}
\hline Test format & $\begin{array}{c}\text { Number of } \\
\text { assays }\end{array}$ & LoD \\
\hline i WarmStart Colorimetric LAMP & 5 & 100 \\
& 4 & 1000 \\
& 1 & 10 \\
ii Separate components & 5 & 100 \\
\hline
\end{tabular}

B

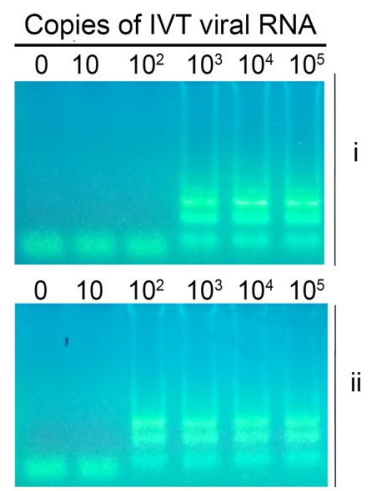

D

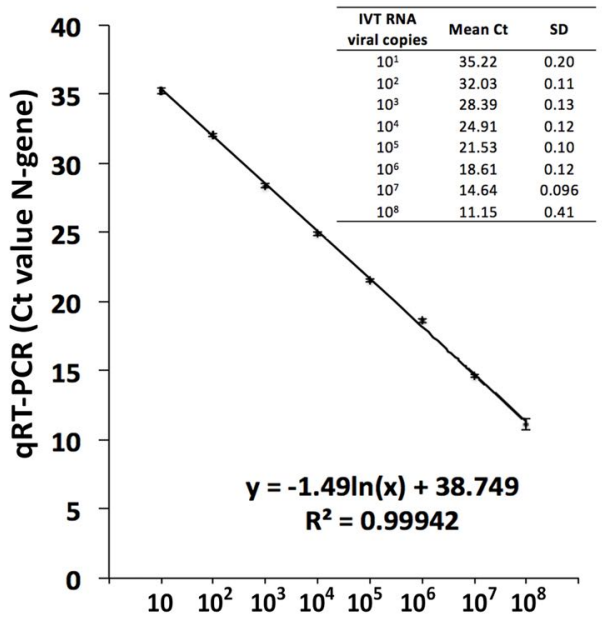

Fig.1 Limit of detection of the two different RT-LAMP formats and of qRT-PCR. (A) A known number of copies of in vitro transcribed (IVT) viral RNA (N-gene) were amplified and detected by colorimetric RT-LAMP using the (i) WarmStart Colorimetric LAMP 2x Master Mix (New England Biolabs) or (ii) the separate components (enzymes purchased individually and an in-house-made colorimetric buffer). The reactions were incubated at $65^{\circ} \mathrm{C}$ for 30 minutes. (B) $10 \mu \mathrm{l}$ of the RT-LAMP reaction were resolved in an agarose gel $(2 \%)$ electrophoresis. The ladder pattern corresponds to the expected LAMP amplification pattern. (C) Limit of detection of ten replicates of the two test formats. (D) Standard curve generated by plotting the number of IVT RNA copies (x-axis) vs. the mean of the corresponding qRT-PCR threshold cycle (Ct) value ( $y$-axis) of three independent experiments. 


\section{Figure 2}

A

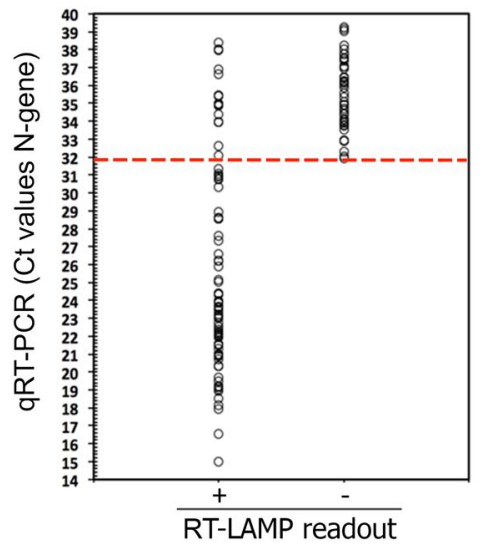

B

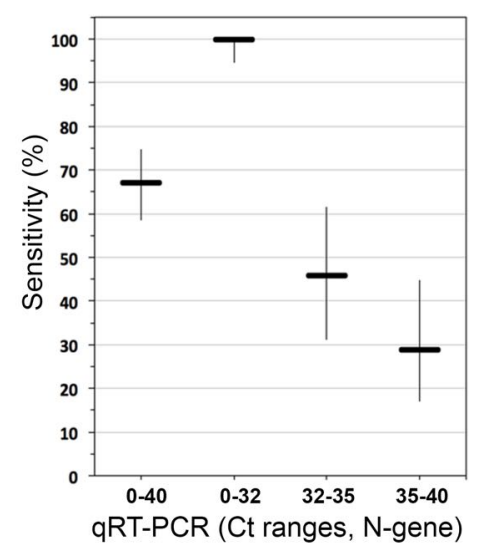

Fig 2. Detection of SARS-CoV-2 in NP samples using RT-LAMP. (A) Comparison of RTLAMP and qRT-PCR results. The Ct values (qRT-PCR results) of 126 COVID-19 positive patients (y-axis) were compared to the RT-LAMP readout (x-axis) taken after 30 minutes of incubation at $65^{\circ} \mathrm{C}$ (positive, +/yellow; negative, - /pink). The dotted red line indicates the $\mathrm{Ct}$ below, which there is $100 \%$ agreement between RT-LAMP and qRT-PCR. (B) Sensitivity of the RT-LAMP assay across different ranges of $\mathrm{Ct}$ values (which reflect different viral loads). The thicker horizontal lines indicate the specificity calculated for the indicated $\mathrm{Ct}$ range (according to the data of panel A and Table 1). The vertical lines indicate the corresponding 95\% confidence intervals. 


\section{Figure 3}

A

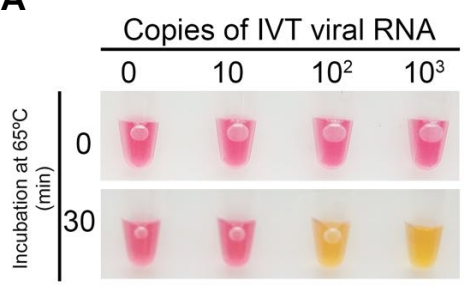

B

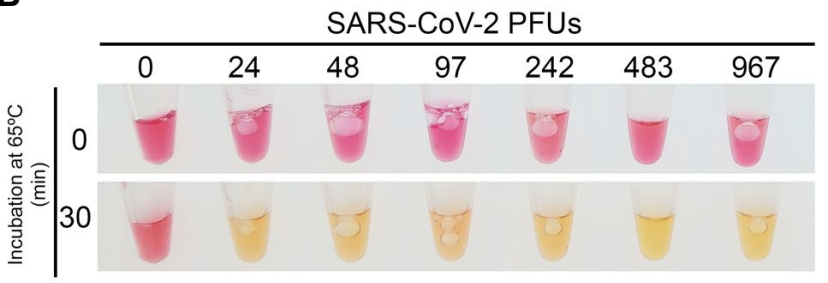

Fig.3 Limit of detection of the saliva RT-LAMP assay. Spike-in experiments of a healthy donor saliva with $(A)$ tenfold dilutions of in vitro transcribed (IVT) viral RNA (N-gene) and (B) in vitro propagated SARS-CoV-2 virions. Saliva samples were processed as described in Material and Methods and $2 \mu \mathrm{L}$ were analyzed by colorimetric RT-LAMP. PFUs - plaque forming units. 


\section{Figure 4}

A COVID-19 patients

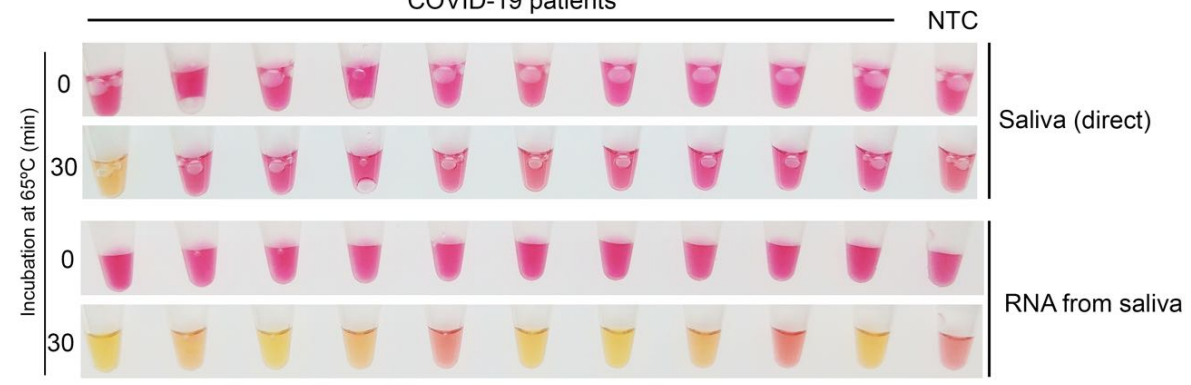

B

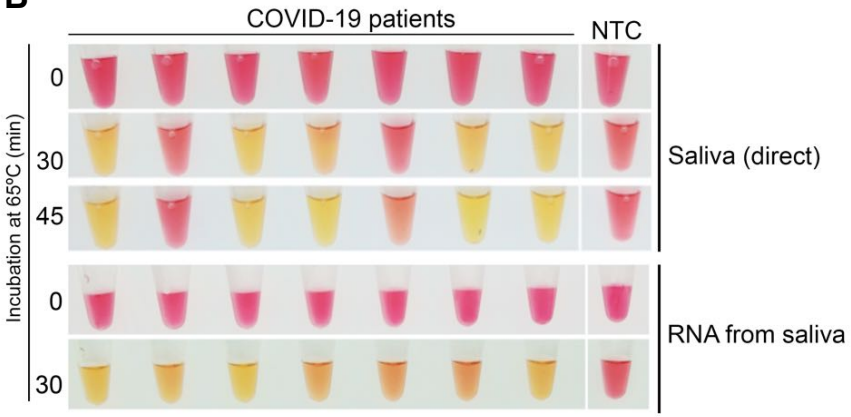

D COVID-19 patients

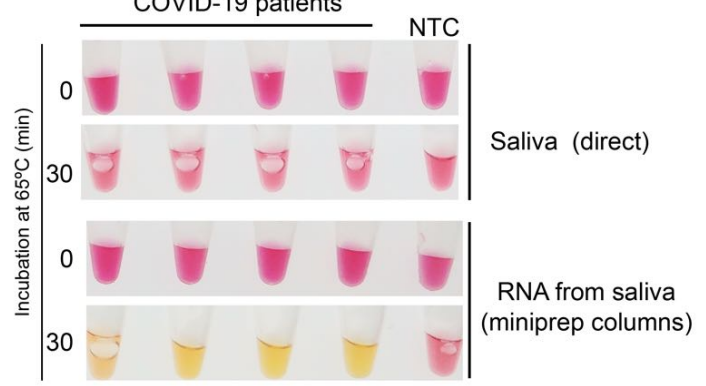

C

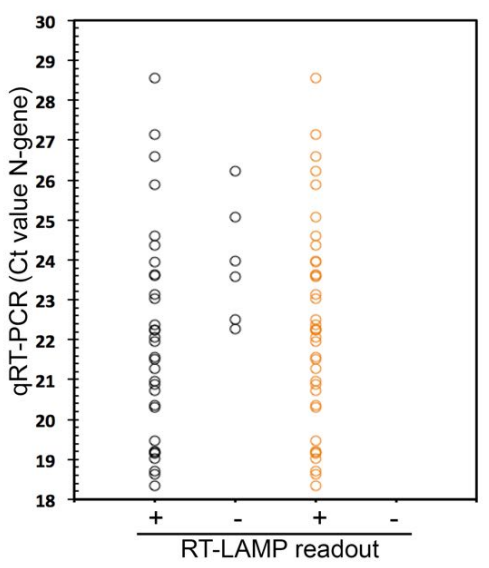

Fig.4 Detection of SARS-CoV-2 in saliva samples using RT-LAMP. RT-LAMP analysis of saliva samples of confirmed COVID-19 patients who (A) induced or not (B) salivation before sample collection. (C) Comparison of RT-LAMP and qRT-PCR results. The Ct values (qRTPCR results) of 39 COVID-19 positive patients (y-axis) were compared to the RT-LAMP readout of the matched saliva samples (x-axis), after 30 minutes of incubation at $65^{\circ} \mathrm{C}$ (positive, + /yellow; negative, - /pink). Black circles - direct saliva; orange circles - RNA extracted from saliva. (D) RNAs from the saliva of false negative samples (as determined by the direct saliva test) were extracted using plasmid DNA miniprep columns (ZR Plasmid Miniprep-Classic Kit, Zymo Research) and re-analyzed. NTC - No template control. 


\section{Figure 5}

A

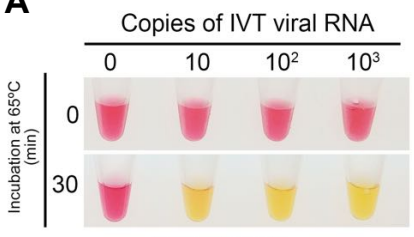

RTx / Bst LF
B

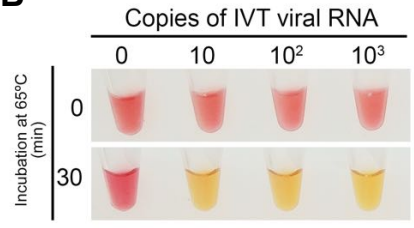

MashUP RT / Bst 2.0
C

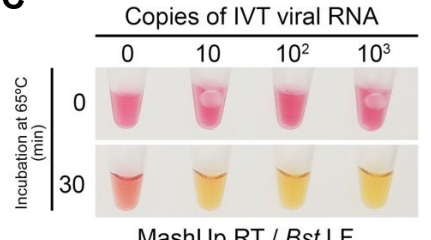

MashUp RT / Bst LF
D

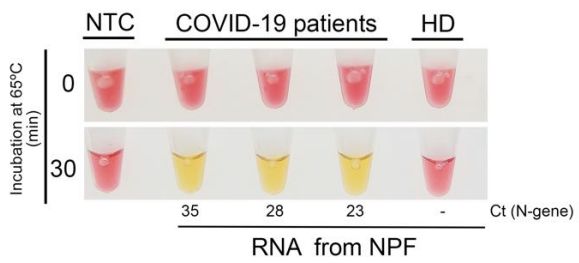

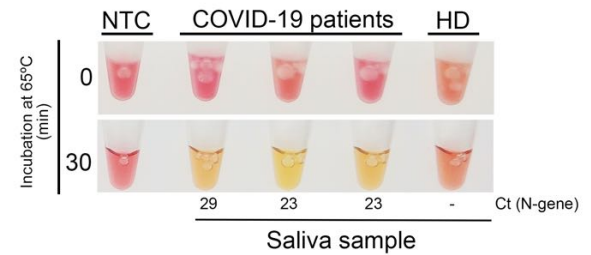

Fig.5 Analytical sensitivity of an in-house-made colorimetric RT-LAMP assay. Tenfold dilutions of in vitro transcribed (IVT) viral RNA (N-gene) were amplified via RT-LAMP and detected using a colorimetric buffer together with (A) RTx (New England Biolabs) and Bst LF (homemade), (B) MashUP RT (homemade) and Bst 2.0 (New England Biolabs) or (C) MashUP RT (homemade) and Bst LF (homemade). The in-house-made setup was next used to detect SARS-CoV-2 sequences in (D) RNAs extracted from the NP fluid (NPF) and (E) saliva samples of COVID-19 positive patients. The reactions were incubated at $65^{\circ} \mathrm{C}$ for 30 minutes. NTC - No template control, HD - Healthy donor. 


\section{Figure 6}

\section{A}

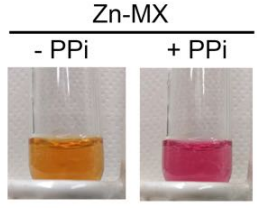

B

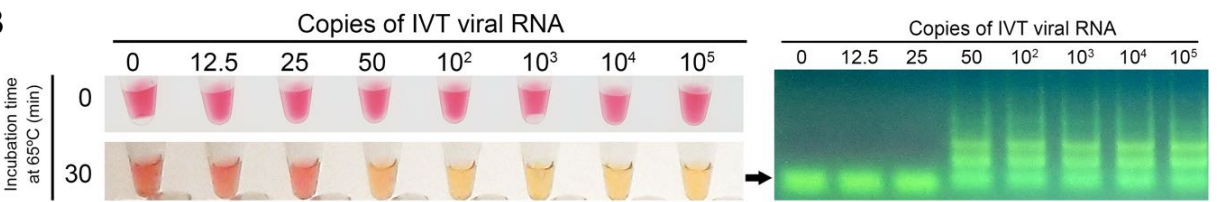

C

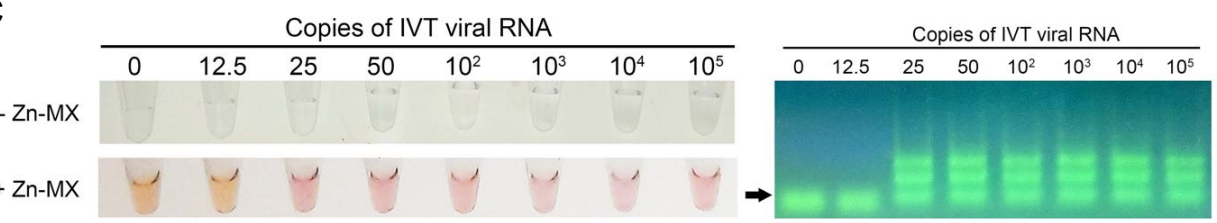

D

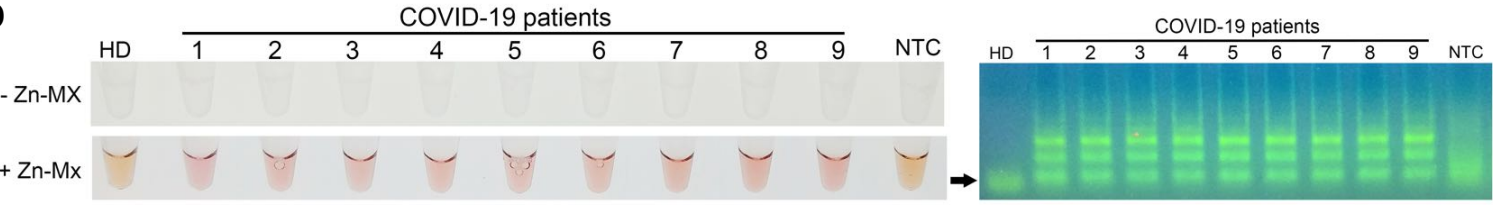

E

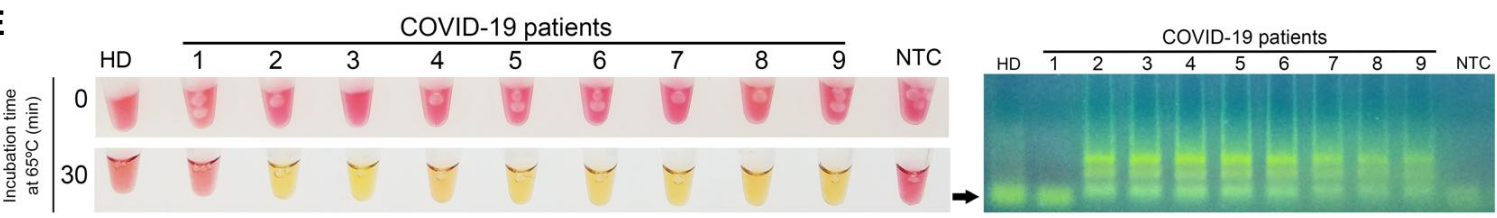

Fig.6 Alternative colorimetric detection based on the complex murexide-zinc. (A) A strong color change from yellow to pink is observed when pyrophostate (PPi) is added to a solution containing Zn-MX. Tenfold dilutions of in vitro transcribed (IVT) viral IVT RNA (Ngene) were amplified via RT-LAMP and detected using phenol red (B) or Zn-MX (C). Amplification was confirmed by agarose gel electrophoresis (AGE). Saliva samples of a healthy donor (HD) and of nine COVID-19 patients were analyzed by RT-LAMP followed by detection with Zn-MX (D) or phenol red (E) and amplification was confirmed by AGE. 


\section{Figures}

A

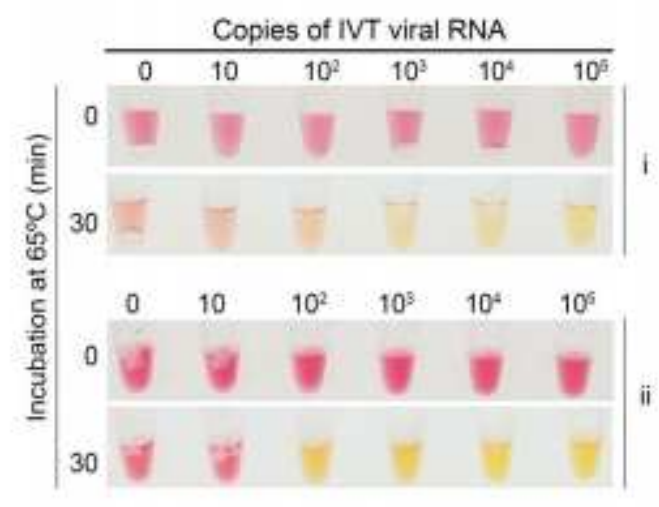

C

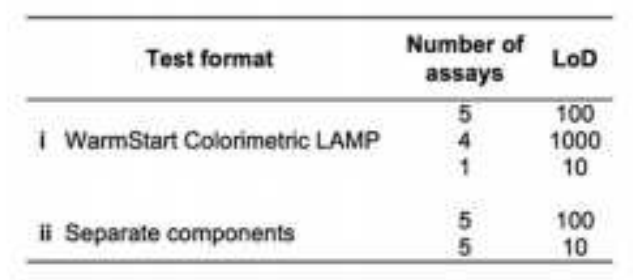

B
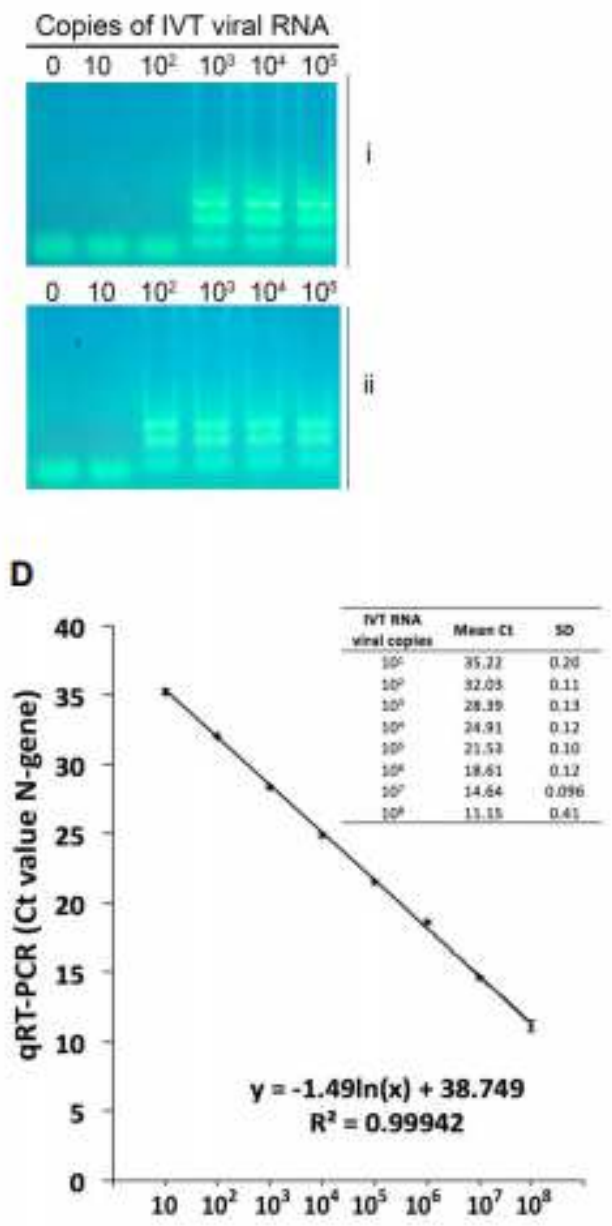

\section{Figure 1}

Limit of detection of the two different RT-LAMP formats and of qRT-PCR. (A) A known number of copies of in vitro transcribed (IVT) viral RNA (N-gene) were amplified and detected by colorimetric RT-LAMP using the (i) WarmStart Colorimetric LAMP 2x Master Mix (New England Biolabs) or (ii) the separate components (enzymes purchased individually and an in-house-made colorimetric buffer). The reactions were incubated at $65^{\circ} \mathrm{C}$ for 30 minutes. (B) $10 \mu \mathrm{l}$ of the RT-LAMP reaction were resolved in an agarose gel (2\%) electrophoresis. The ladder pattern corresponds to the expected LAMP amplification pattern. (C) Limit of detection of ten replicates of the two test formats. (D) Standard curve generated by plotting the number of IVT RNA copies (x-axis) vs. the mean of the corresponding qRT-PCR threshold cycle (Ct) value ( $y$-axis) of three independent experiments. 
A

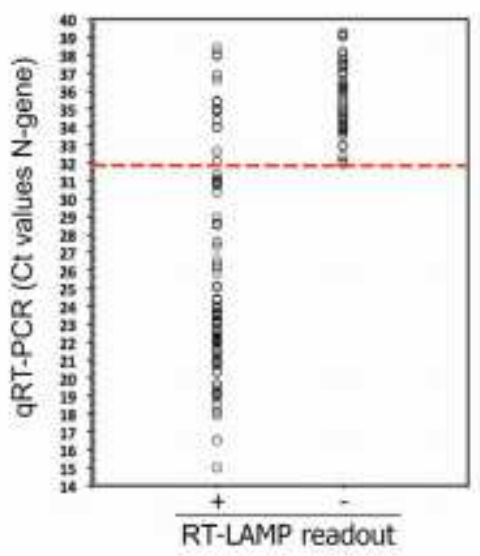

B

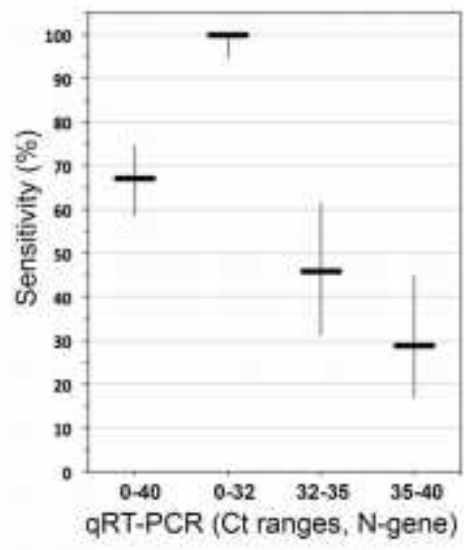

Figure 2

Detection of SARS-CoV-2 in NP samples using RT-LAMP. (A) Comparison of RTLAMP and qRT-PCR results. The $\mathrm{Ct}$ values (qRT-PCR results) of 126 COVID-19 positive patients (y-axis) were compared to the RT-LAMP readout (x-axis) taken after 30 minutes of incubation at $65^{\circ} \mathrm{C}$ (positive, + /yellow; negative, /pink). The dotted red line indicates the Ct below, which there is $100 \%$ agreement between RT-LAMP and qRT-PCR. (B) Sensitivity of the RT-LAMP assay across different ranges of $\mathrm{Ct}$ values (which reflect different viral loads). The thicker horizontal lines indicate the specificity calculated for the indicated $\mathrm{Ct}$ range (according to the data of panel A and Table 1). The vertical lines indicate the corresponding 95\% confidence intervals.

A

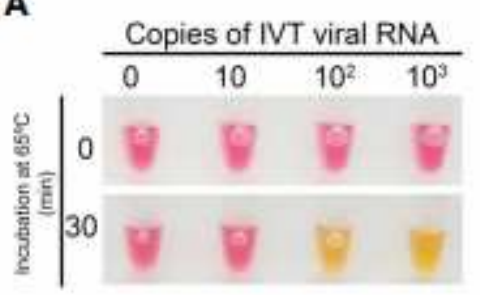

B

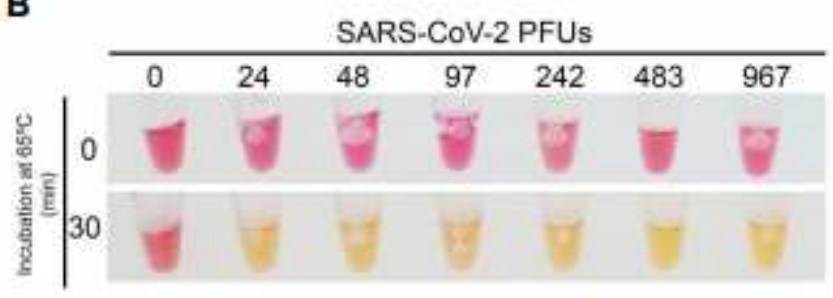

\section{Figure 3}

Limit of detection of the saliva RT-LAMP assay. Spike-in experiments of a healthy donor saliva with (A) tenfold dilutions of in vitro transcribed (IVT) viral RNA (N-gene) and (B) in vitro propagated SARS-CoV-2 virions. Saliva samples were processed as described in Material and Methods and $2 \mu \mathrm{L}$ were analyzed by colorimetric RT-LAMP. PFUs - plaque forming units. 

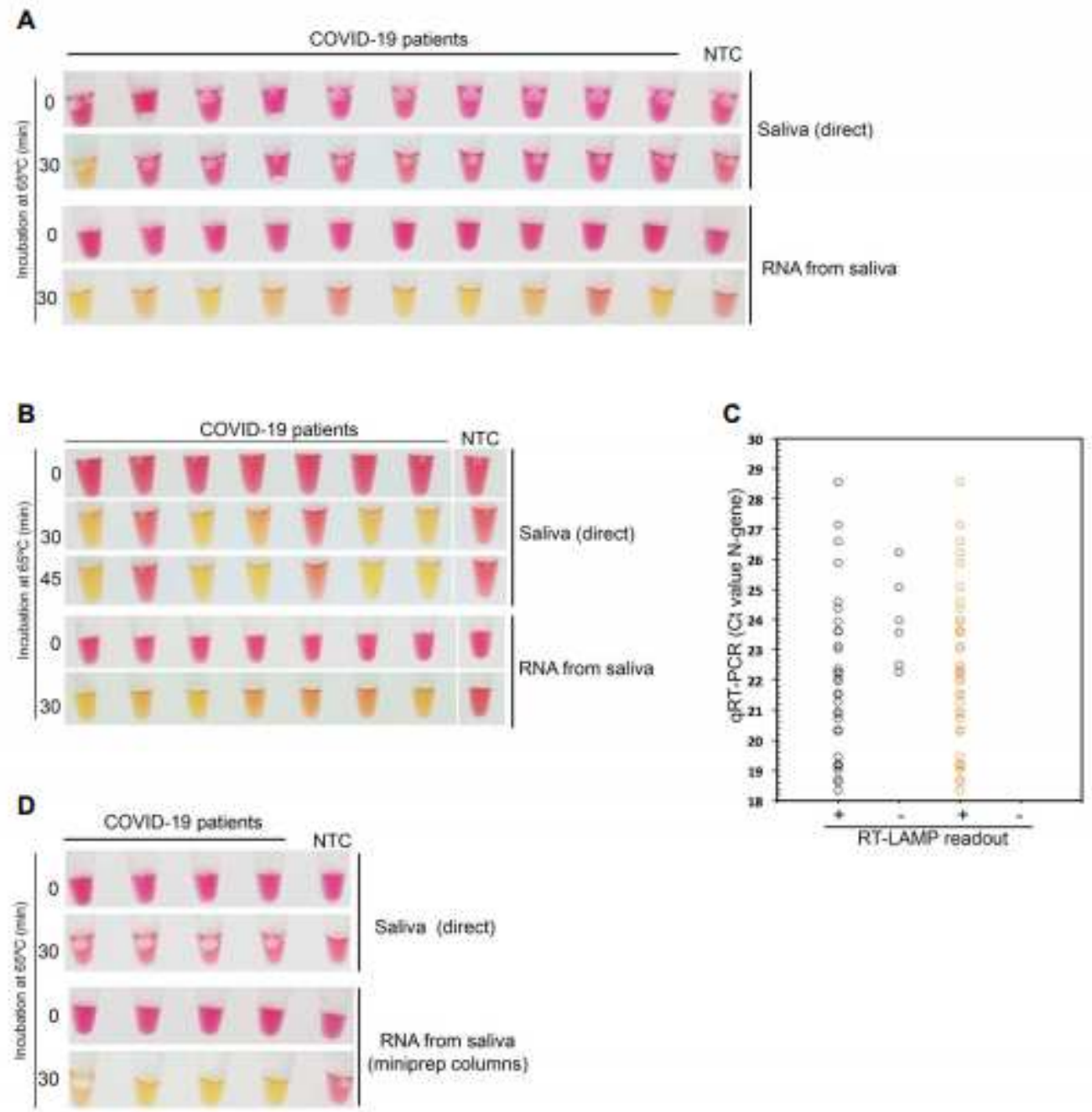

\section{Figure 4}

Detection of SARS-CoV-2 in saliva samples using RT-LAMP. RT-LAMP analysis of saliva samples of confirmed COVID-19 patients who (A) induced or not (B) salivation before sample collection. (C) Comparison of RT-LAMP and qRT-PCR results. The Ct values (qRTPCR results) of 39 COVID-19 positive patients (y-axis) were compared to the RT-LAMP readout of the matched saliva samples ( $x$-axis), after 30 minutes of incubation at $65^{\circ} \mathrm{C}$ (positive, $+/$ yellow; negative, $-/$ pink). Black circles - direct saliva; orange circles - RNA extracted from saliva. (D) RNAs from the saliva of false negative samples (as determined by the direct saliva test) were extracted using plasmid DNA miniprep columns (ZR Plasmid MiniprepClassic Kit, Zymo Research) and re-analyzed. NTC - No template control. 


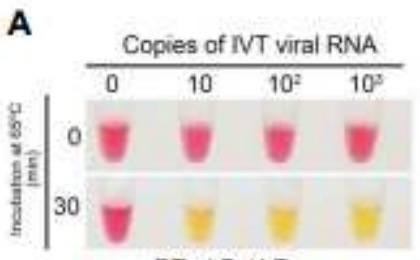

RTx / Bst LF

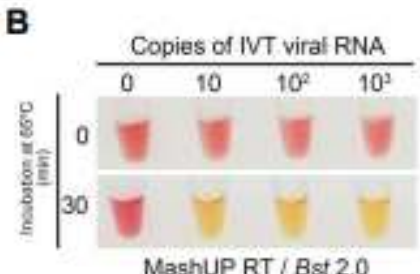

MashUP RT / Bst 2.0

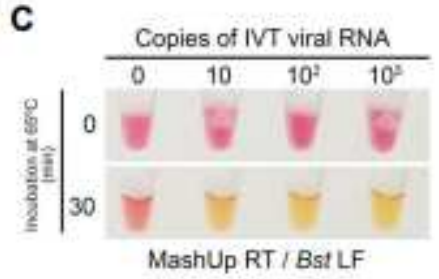

E

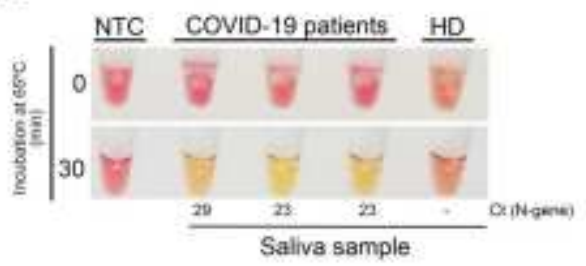

\section{Figure 5}

Analytical sensitivity of an in-house-made colorimetric RT-LAMP assay. Tenfold dilutions of in vitro transcribed (IVT) viral RNA (N-gene) were amplified via RT-LAMP and detected using a colorimetric buffer together with (A) RTx (New England Biolabs) and Bst LF (homemade), (B) MashUP RT (homemade) and Bst 2.0 (New England Biolabs) or (C) MashUP RT (homemade) and Bst LF (homemade). The in-housemade setup was next used to detect SARS-CoV-2 sequences in (D) RNAs extracted from the NP fluid (NPF) and (E) saliva samples of COVID-19 positive patients. The reactions were incubated at $65^{\circ} \mathrm{C}$ for 30 minutes. NTC - No template control, HD - Healthy donor. 
A
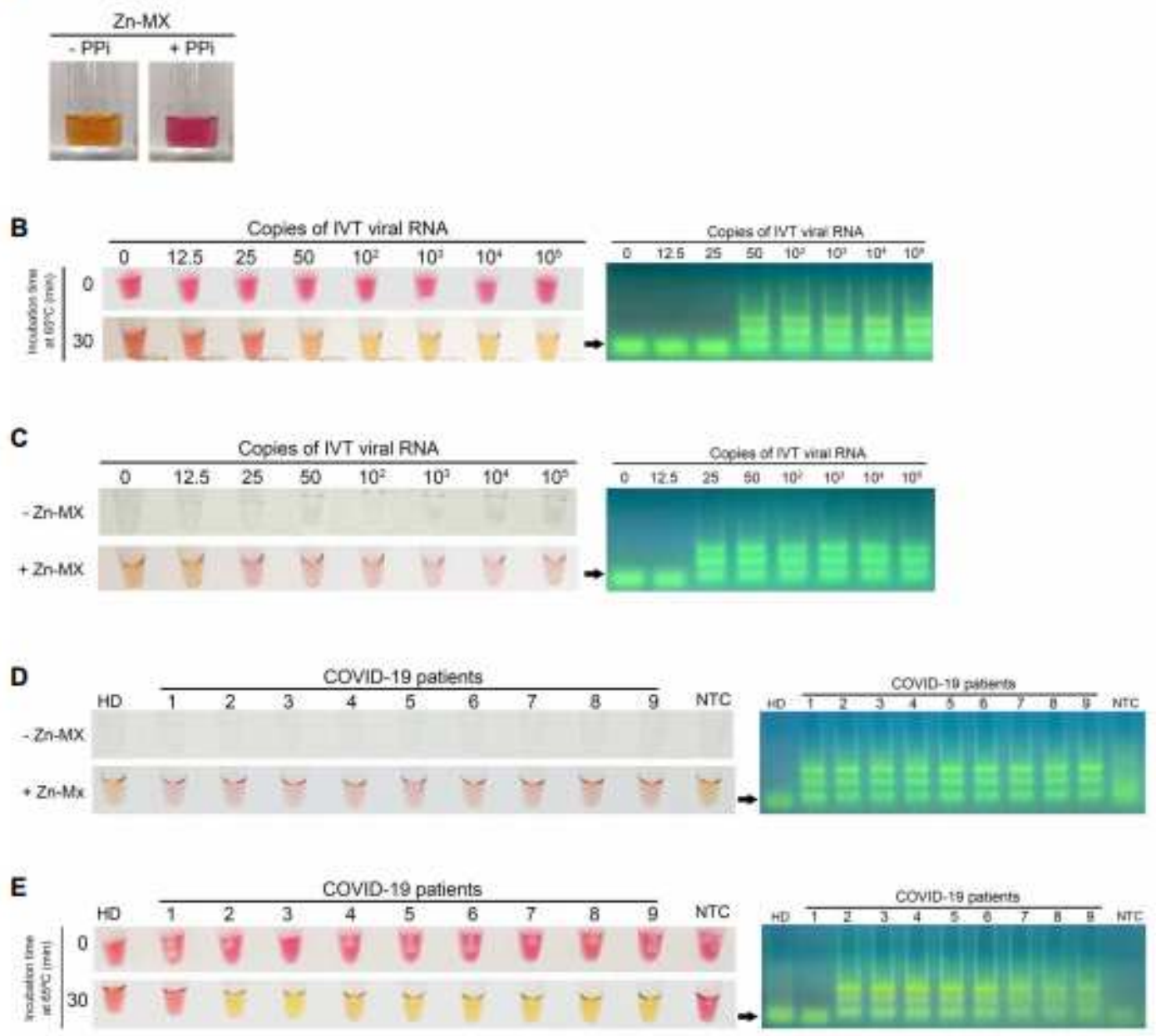

\section{Figure 6}

Alternative colorimetric detection based on the complex murexide-zinc. (A) A strong color change from yellow to pink is observed when pyrophostate (PPi) is added to a solution containing Zn-MX. Tenfold dilutions of in vitro transcribed (IVT) viral IVT RNA (Ngene) were amplified via RT-LAMP and detected using phenol red (B) or Zn-MX (C). Amplification was confirmed by agarose gel electrophoresis (AGE). Saliva samples of a healthy donor (HD) and of nine COVID-19 patients were analyzed by RT-LAMP followed by detection with Zn-MX (D) or phenol red (E) and amplification was confirmed by AGE.

\section{Supplementary Files}

This is a list of supplementary files associated with this preprint. Click to download.

- SupplementaryMaterial.pdf 